УДК $316: 43$

$10.17213 / 2075-2067-2020-5-53-64$

\title{
САМОРЕГУЛЯЦИЯ ПОЛИТИЧЕСКОЙ ЖИЗНИ КРЫМСКОЙ МОЛОДЕЖИ ${ }^{1}$
}

\author{
(C) 2020 г. А. В. Дятлов, В. В. Ковалев, А. Б. Понамарев
}

\section{Южный федеральный университет, г. Ростов-на-Дону, Россия}

Цель исследования состоит в том, чтобы показать особенности саморегуляции политической жизни крымской молодежи в условиях интеграџии региона в состав Российской Федерации.

Методологическая база исследования основывается на феноменологической социологии А. Шюия, которая применяется для объяснения прочессов саморегуляциии политической жизни молодежи Крыма, а в конкретно-прикладном аспекте - массовом соииологическом опросе, проведенном в Крымском федеральном университета (КФУ).

Результаты исследования. Установлено, что в основе саморегуляции лежсит проявление компенсаторной функиии, связанной с замещением недостатка внешней организующей силь, необходимой для сохранения устойчивости сочиального взаимодействия. Структура политической саморегулячии описана нами через операџионализаџию таких понятий, как политические потребности, интересы, установки и ценности, в комплексе образующие определенньй тип политического сознания. Показано, что неопределенность и неустойчивость, порождающие потребность в самоорганизачии, для молодежи Крыма свойственны в большей степени, чем для их сверстников из других регионов России. Это обусловлено процессами ресоциализации, замены одного типа политического сознания другим. Выявлено, что большая часть молодежи позитивно очуенивает вхождение Крыма в состав России и видит те новые возможности, которые это объединение им предоставляет. Но имеется и определенная группа, потенциально способная искать и ищущая в реальной политике альтернативные формы саморегуляиии. Данная группа показывает масштаб протестного потенциала среди молодежи Крыма.

Перспективы дальнейших исследований авторы видят в проведении мaсcoвblх coииологических опросов студенческой молодежи с выявлением региональных особенностей Крылма: западной, южной и восточной частей полуострова, преследуя цель более четкого выделения групп факторов, оказывающих воздействие на прочессы политической самоорганизачии, в том числе протестного характера.

Ключевые слова: молодежь; Крым; саморегуляиия; политическая идентичность; интересы; потребности; политическая ресоџиализаџия; социальные проблемы; адаптация.

\section{SELF-REGULATION OF POLITICAL LIFE CRIMEAN YOUTH}

\author{
(C) 2020 A. V. Dyatlov, V. V. Kovalev, A. B. Ponamarev
}

Southern Federal University, Rostov-on-Don, Russia

1 Статья выполнена в рамках реализации гранта РФФИ, проект №20-011-00585A «Саморегуляция жизнедеятельности молодежи в изменяющейся социальной реальности». 
The aim of the study is to show the peculiarities of self-regulation of political life of Crimean youth in the context of integration of the region into the Russian Federation.

The methodological basis of the research is based on the phenomenological sociology of A. Shyutz, which is used to explain the processes of self-regulation of political life of young people in Crimea, and in a specifically applied aspect - a mass sociological survey conducted at the Crimean Federal University (KFU).

Research result. It is established that self-regulation is based on the manifestation of the compensatory function associated with replacing the lack of external organizing force necessary to maintain the stability of social interaction. The structure of political self-regulation is described by us through the operationalization of such concepts as political needs, interests, attitudes and values, which together form a certain type of political consciousness. It is shown that the uncertainty and instability that generate the need for self-organization are more common for young people in Crimea than for their peers from other regions of Russia. This is due to the processes of re-socialization, replacing one type of political consciousness with another. It is revealed that the majority of young people positively assesses the entry of Crimea into Russia and sees the new opportunities that this Association provides them. But there is also a certain group that is potentially able to search for alternative forms of self-regulation in real politics. This group shows the scale of the protest potential among the youth of Crimea.

The authors see the prospects for further research in conducting mass sociological surveys of students with the identification of regional features of the Crimea: the Western, southern and Eastern parts of the Peninsula, with the aim of more clearly identifying groups of factors that affect the processes of political self-organization, including protest.

Key words: youth; Crimea; self-regulation; political identity; interests; needs; political resocialization; social problems; adaptation.

Введение. Проблема саморегуляции политической жизни крымской молодежи не может считаться надуманной. В связи с интеграцией региона в состав Российской Федерации она значима для всех возрастных групп полуострова, но именно для молодежи особенно актуальна в связи с тем, что данная возрастная группа оказалась в Крыму единственной, для кого Россия по сути своей является экзогенной политической реальностью. У многих её представителей процесс политической и гражданской идентичности на этапе перехода из детства в отрочество и юность неразрывно связывался с Украиной, а некоторые из тех, кто в 2018 году принимал участие в президентских выборах, были даже ровесниками распада СССР и, соответственно, рождения украинской государственности. Неудивительно, что молодежь Крыма переживает сейчас трудности политической ресоциализации, при этом в отличие от поколения своих родителей и людей ещё более старшего возраста в 2014 год, когда со- стоялся референдум, она входила, не имея индивидуально значимых каналов исторической памяти, по которым бы передавалась информация о неразрывной связи Крыма и России. В самом деле, система образования в школах Украины выстроена таким образом, чтобы раздробить единый исторический процесс на украинский и российский за счет принижения значимости последнего в пользу первого. С учётом высокой степени восприимчивости детского сознания к информации это неизбежно повлияло на развитие антироссийских настроений у крымской молодежи, во всяком случае, способствовало увеличению политической дистанции между молодежью двух соседних стран. Безусловно, российская власть осознает все эти трудности. Некоторые из них стали очевидными практически сразу после возвращения полуострова в состав России. Так, громким сигналом 25 мая 2014 года прозвучало исполнение гимна Украины выпускниками одной из ялтинских гимназий [1]. И пусть через 
некоторое время выяснилось, что это были школьники единственного в Крыму учебного заведения, где преподавание осуществлялось на украинском языке, совсем игнорировать подобные инциденты власть не могла, поэтому сейчас условиям жизни крымской молодежи уделяется особенное внимание: предпринимаются усилия по улучшению социально-экономической инфраструктуры региона, обеспечиваются возможности для поступления в российские вузы, много времени отводится патриотическому воспитанию. Однако полностью организовать молодежь во всех её интеракциях и поставить под жесткий контроль формирование её политического сознания - задача не решаемая. В связи с этим большую роль продолжают играть процессы саморегуляции, способные принимать самые разнообразные формы и по идеологической наполняемости, и по характеру совершаемых действий. Таким образом, цель нашего исследования состоит в том, чтобы показать особенности саморегуляции политической жизни крымской молодежи в условиях интеграции региона в состав Российской Федерации.

\section{Теоретико-методологические основы} и методы исследования. Под саморегуляцией в социологии обычно понимается способность сложных социальных систем, макро- и микрогрупп, а также отдельных социальных акторов компенсировать недостаток внешней организующей силы для сохранения устойчивости социального взаимодействия. В таком понимании главная функция саморегуляции - компенсаторная. Особое значение она приобретает в условиях социальной разбалансированности, которая проявляется через множество несогласованных между собой целей, ценностей, интересов, свойственных разным группам социальных акторов. При этом несогласованность имеет место как в экзогенных социальных группах, внося разлад в функционирование локальных сообществ, так и в эндогенных, порой нарушая нормальную жизнедеятельность всего региона. В принципе, каждый социум в идеале должен обладать способностью к саморегуляции, и в той или иной мере он такой способностью обладает. Эта мера, прежде всего, зависит от осознаваемой готовности социальных акторов к согласованию разнонаправленных интересов для участия в совместной деятельности. Но в обществе позднего модерна это становится осуществлять заметно труднее, чем в традиционном: потребности всё больше приобретают многовекторный характер, а социальные традиции и стереотипы разрушаются, переставая играть роль социальных скрепов, способных быть надежной платформой для саморегуляции социального поведения [2]. В итоге социокультурная матрица на нижних уровнях, где расположены пласты, ответственные за регуляцию сферы подсознания, постепенно разрушается, а в верхних слоях, где происходит процесс выработки осознаваемых и воспроизводимых в сознании интересов и ценностей, имеет место её укрупнение. С одной стороны, это повышает значимость индивидуально принимаемых социальными акторами решений, их личную ответственность за те последствия, которые от них могут последовать, а с другой, в социуме становится более существенной роль лидеров мнений, разного рода неформальных групп, абсорбирующих в себя социально инертную массу молодежи, не способную к постановке и решению задач индивидуального характера.

Методологически процесс саморегуляции описан в феноменологической социологии А. Шюца. В качестве базового социолог избирает такое понятие, как естественная установка [3]. Она интерпретируется ученым в виде инструмента, посредством которого актор в отношении социальной коммуникации определяет, что есть индивидуализированное, а что типичное. Это разделение формирует образуемые в процессе саморегуляции сообщества, дифференцируемые субъектно через артикуляцию потребностей, выступающих естественным импульсом к социальному взаимодействию. Наличие обнаруживаемых типичностей создает условный потенциал способности молодежи к включенности в процессы саморегуляции. При этом промежуточная цель поисковой активности на основе естественной установки направлена на подавление рефлексивности, то есть намерения воспроизводить индивидуализированные смыслы. Подобное состояние он характеризует как «рациональное действие», которое «всегда действие в рамках непроблематизированного и неопределенного 
набора типизаций мотивов, средств и целей, способов действия и персон, его выполняющих, принимаемых в качестве само собой разумеющихся. Они, однако, принимаются как сами собой разумеющиеся не только самим действующим, но и его партнером» [3, с. 1011]. А. Шюц определяет это как подавление очагов напряженности в пространстве жизненных смыслов, сокращение проблемных интеракций, способных поддерживать социальную неустойчивость и неопределенность.

Рассмотренная социальная модель может быть применена в качестве объясняющей социальные процессы саморегуляции политической жизни молодежи через категорию рефлексивности, посредством которой мы можем показать, каким образом осуществляется переход потребностей на уровень осмысления интересов. Что касается понятия «интерес», то мы в своей оценке заинтересованности молодежи в политическом участии будем придерживаться определения, данного Д.В. Александровым. В соответствии с его пониманием «интерес - это рациональноценностная позиция социального субъекта относительно обеспечения условий и способов своей жизнедеятельности и поведения в обществе» $[4$, с. 65$]$. С данной точки зрения интерес представляет собой внешнее выражение отрефлексированной адаптационной стратегии, связывающей воедино политические потребности и социальные возможности субъекта. Применяя данное определение к предмету нашей статьи, отметим, что политическая саморегуляция становится возможной только в том случае, если социальный актор оказывается способным самостоятельно выработать необходимые адаптационные стратегии, которые на внешнем уровне развития его политического сознания станут формировать соответствующие интересы в области политического участия. Осознание не только потребностей, но и возможностей их удовлетворения происходит «на вторичной стадии социализации, которая характеризуется, прежде всего, развитием способности к активному познанию, осмыслению и переосмыслению, т.е. рефлексии» [5, с. 30].

Устойчивость интересов зависит не только от особенностей рефлексивного опыта отдельного социального актора. В конечном итоге в социологии этот опыт не становится объектом самостоятельного изучения, независимо от глубины и качества рефлексивных способностей познающего субъекта. Он поглощается в поисках тех условий и оснований, которые обеспечивают формирование более широкого социального пространства. Решение этой задачи в предметном пространстве социологии осуществляется на основе применения такого понятия, как социальная установка. Под последней вслед за С. С. Гордеевой мы будем понимать «готовность субъекта совершать конкретные действия в определенных ситуациях, способствующих удовлетворению актуализированных потребностей на основании эмоционально окрашенного оценочного отношения к социальному объекту» [6, с. 139]. Через социальную установку реализуется не столько структурирование и цементирование индивидуальных интересов, сколько образование референтных групп политического участия молодежи, в которых поддерживаются и реализуются коллективные интересы политических единомышленников. Таким образом, социальная установка обеспечивает трансформацию индивидуальных переживаний личного опыта по удовлетворению потребностей и реализации интересов в переживания коллективные, что приводит к образованию устойчивых молодежных групп в области политических отношений, формирующихся как результирующий итог процессов самоорганизации.

Когда социальные установки начинают играть роль социокультурного регулятора, их устойчивость в этом качестве и равным образом эффективность зависят от того, насколько они оказались отрефлексированными познающим субъектом. Следовательно, речь идет о социальных ценностях. Понимание ценностей, лежащее в основе использования этого термина в данной статье, будет основываться на классическом определении, предложенном американскими социологами У. Томасом и Ф. Знанецким в их совместном труде «Польский крестьянин в Европе и Америке». В указанной работе читаем следующее: «Под социальной ценностью мы понимаем любой предмет, обладающий эмпирическим содержанием, доступным членам социальной группы, а также значением, вследствие которого он является или может быть объектом действия» [7, с. 109]. Ценность продуцирует 
возникновение социальной солидарности, поскольку создание единой шкалы оценки значимостей социальных объектов поддерживает групповую сплоченность и наличие системных связей, в основе которых лежат ролевые модели поведения, созданные таким образом, чтобы группа была одновременно и дифференцированной, и единым целым.

Итак, трансформация потребностей в интересы, воспроизводство на их основе социальных установок и ценностей в конечном итоге приводит к образованию пространства группового политического сознания, где социальные акторы обладают типизированными относительно друг друга мотивами к совершению политических действий. Одна из важнейших характеристик примирительно к молодежи заключается в том, что социальные условия, порождающие условия её социализации, характеризуются более высоким уровнем неопределенностей и нестабильности. Надо понимать, что описанный механизм всего лишь упорядочивает процессы создания типичностей, но не приводит к абсолютному единообразию в социальной реальности. В итоге в сознании разных групп акторов возникает нацеленность на воспроизводство устойчивых социальных форм для деятельности в групповых сообществах, где имеются альтернативные господствующим типам культуры программы поведения. Молодежь в силу характеристик, присущих именно этой возрастной группе, имеет устойчивые мотивы к более активной деятельности, чем иные возрастные когорты. Спонтанность условий, в которых формируется политическое сознание молодежи, рождает неопределенность, неструктурированность. Это, в свою очередь, ведет к потере управляемости, а поэтому обуславливает особо острую потребность в саморегуляции своей деятельности.

Всё сказанное свойственно в большей степени молодежи Крыма, чем этой же возрастной группе из других регионов России. Если на материке, как нередко выражаются в Крыму, молодые люди проходят «дежурную» социализацию, включаясь в сложившуюся матрицу из политических ценностей, норм и ролей, то на полуострове заявленная «спонтанность условий» по разным причинам, о которых мы напишем ниже, имеет куда большую вариативность, нежели в остальной России.
Анализ особенностей саморегуляции политической жизни молодежи Крыма в условиях интеграции региона в состав Российской Федерации был осуществлен в ходе социологического опроса студентов Крымского федерального университета (КФУ), реализованного в два этапа: 12-20 февраля и 12-13 марта 2018 года. Исследование проводилось с целью выполнить анализ основных характеристик электорального поля КФУ (студенты) по параметрам оценки политической, экономической и социально-психологической ситуации в Крыму, а также по основным параметрам электорального поведения - электоральной активности, определенности, устойчивости и мотивации выбора. Всего в опросе приняли участие 1400 студентов структурных подразделений и филиалов КФУ. Дополнительно к этому применялся метод анализа документов, среди которых преобладали такие источники эмпирической информации, как СМИ на электронных носителях, социальные сети, интернет-блоги.

Результаты исследования. Оценка процессов саморегуляции, проходящих в политической жизни крымской молодежи, будет осуществляться с применением трех эмпирических индикаторов: 1) удовлетворенность положением дел в регионе (стране); 2) артикуляция трудностей; 3) готовность включаться в альтернативные программы политического участия. Эти три индикатора находятся в тесной взаимосвязи между собой, т.к. отражают наличие психологического фона для иных форм политического участия, социальные основания для неудовлетворенности результатами официальной политики и осмысление способов политического участия, непредусмотренных в рамках желаемых или одобряемых процедур.

Обратимся к вопросу об удовлетворенности положением дел в регионе (стране).

Глубоких различий между региональной и общефедеральной оценкой не выявлено. Это подтверждается и другим вопросом из анкеты, которым предлагается осуществить непосредственное сравнение качества жизни в Республике Крым по сравнению с другими регионами России. Варианты «лучше» и «в нашем регионе люди живут в среднем так же, как и в большинстве дру- 
Удовлетворенность студентов положением дел в Республике Крым (стране), в \%

\begin{tabular}{|l|c|c|}
\hline \multirow{2}{*}{\multicolumn{1}{|c|}{ Варианты ответов }} & \multicolumn{2}{|c|}{ Полученный результат, в \% } \\
\cline { 2 - 3 } & В Республике Крым & В Российской Федерации \\
\hline Удовлетворен & 10,4 & 4,8 \\
\hline Скорее удовлетворен & 34,88 & 38,08 \\
\hline Скорее не удовлетворен & 28,8 & 28,16 \\
\hline Совершенно не удовлетворен & 12,96 & 13,6 \\
\hline Затрудняюсь ответить & 12,96 & 15,36 \\
\hline
\end{tabular}

Таблица 2

Проблемы, которые являются острыми лично для Вас, в \%

\begin{tabular}{|l|c|}
\hline \multicolumn{1}{|c|}{ Варианты ответов } & $\begin{array}{c}\text { Полученный } \\
\text { результат, в \% }\end{array}$ \\
\hline Рост цен на товары и услуги & 36 \\
\hline Рост тарифов на жилищно-коммунальные услуги, квартплату & 32 \\
\hline Плохие дороги, плохая работа транспорта & 30 \\
\hline Низкий уровень медицинских услуг, плохая работа органов здравоохранения & 28,8 \\
\hline Низкие зарплаты & 28,4 \\
\hline Коррупция, плохая работа и произвол чиновников & 24,4 \\
\hline Низкое качество жилищно-коммунальных услуг & 24,4 \\
\hline Низкие пенсии & 21,2 \\
\hline Плохое состояние окружающей среды, экологические проблемы & 19,2 \\
\hline Трудности с выездом за границу & 17,2 \\
\hline $\begin{array}{l}\text { Проблемы нравственного состояния общества, низкий уровень морали, } \\
\text { равнодушие окружающих людей }\end{array}$ & 16,8 \\
\hline Угроза безработицы & 16 \\
\hline Распространенность пьянства, алкоголизма, наркомании & 14,4 \\
\hline Приезд в регион большого количества новых жителей, мигрантов & 13,6 \\
\hline Нехватка жилья, плохое качество, ветхость жилья & 12,8 \\
\hline Угроза террористических актов & 12 \\
\hline Межнациональные проблемы & 9,2 \\
\hline Низкий уровень системы образования в регионе (школы, училища, вузы) \\
\hline Высокий уровень преступности & 2 \\
\hline Другое & 2 \\
\hline
\end{tabular}


гих регионов страны, в чем-то хуже, в чем-то лучше» выбрали в совокупности $63,36 \%$ респондентов. Согласие с альтернативной позицией «в нашем регионе люди в основном живут хуже, чем в большинстве других регионов страны» высказали 28,32\% от числа всех опрошенных. Наличие совпадений в ответах только облегчает нам выход на целостное понимание того, что саморегуляция молодежи в политической сфере зависит не от осознания отсталости от других регионов России, а от неприятия конкретных проблем социально-экономического характера самого региона проживания. Вопрос заключается только в том, были ли эти проблемы всегда, в том числе в украинский период жизни полуострова, или они стали следствием вхождения Крыма в состав России. На самом деле, это важно, поскольку данный аспект напрямую связан с той схемой, которую мы сконструировали в теоретико-методологической части статьи. По линии социального недовольства можно выстроить комбинацию понятий, через которые мы описали механизм саморегуляции. В конечном итоге за представленными цифрами, свидетельствующими в данном качестве лишь о глубине психологического фона, на котором произрастают импульсы политического недовольства, можно попытаться увидеть реальные мотивы, способные действовать как факторы политической самоорганизации. Даже простой линейный замер выявляет, что в Крыму имеется около 40\% потенциально недовольных своим положением студентов. Это означает, что, как минимум, именно такое количество студентов способно выбирать альтернативные официальным формы политической саморегуляции.

Наличие большого количества молодежи, неудовлетворенной положением дел в регионе, актуализирует потребность понять, какие проблемы служат основанием для этого.

Нетрудно заметить, что на верхних этажах пирамиды из лично актуализированных проблем располагаются трудности социально-экономического характера. Безусловным лидером оказался «рост цен на товары и услуги» $(36,0 \%)$. В значительной степени это является прямым следствием вхождения полуострова в состав России. Рост цен в перспективе мог бы быть компенсирован ростом показателей развития, однако есть один ас- пект этой проблемы, который нельзя исправить простым выравниванием качества жизни населения полуострова под общероссийские стандарты. Речь идет об утрате крайне удобной для украинского периода практики, когда наличие разного диапазона цен в Крыму и России позволяло российским туристам за одинаковую сумму денег потреблять на полуострове значительно больший объем благ, чем у себя на родине. Теперь цены подравнялись, говорят даже о так называемой «революции цен», и это привело к снижению покупательских возможностей граждан России в Крыму. А между тем, они во многом теперь являются единственными потребителями туристического продукта: из-за санкций иностранцы в Крым приехать не могут, а украинцы по известным причинам не хотят.

О значимости ценовой революции в восприятии самой молодежи Крыма может свидетельствовать тот факт, что при ответе на другие вопросы, связанные со стратегией развития региона, респонденты выбирали ответы, нацеливающие перспективы развития Крыма как международного туристического центра. Так, вариант ответа «регион должен развиваться как туристическая зона, производитель экологически чистых сельхозпродуктов, как экологический заповедник» выбрали 49,28\% респондентов, а близкую ему по стратегии реализации формулировку «регион должен развиваться как "свободный порт", “окно", торговые "ворота" из России во внешний мир, и из внешнего мира в Россию» $-21,44 \%$.

Также видно, что молодежь серьезно обеспокоена дефектами в социально-экономической инфраструктуре (транспорт, ЖКХ, дороги и т.д.), что частично можно считать наследием от украинского периода (транспорт и дороги), но также имеет следствия в связи с особенностями новой российской политики (рост оплаты за ЖКХ). Другие вопросы, например, проблемы духовно-нравственного характера, защита безопасности, низкий уровень образования, рост преступности, межнациональные противоречия оказались не столь значимыми при оценке их личностной актуальности.

Вне всякого сомнения, большая часть молодежи позитивно оценивает вхождение Крыма в состав России и видит те новые воз- 
можности, которые это объединение им предоставляет. Но имеется и определенная группа, которую далее нам предстоит определить количественно, потенциально способная искать и ищущая в реальной политике альтернативные формы саморегуляции в политической сфере.

В качестве обоснования мы можем сослаться на ряд полученных в процессе соцопроса данных, свидетельствующих о поиске иных векторов политического развития для Крыма и, вероятно, личного движения по данным направлениям.

Социальные сети, разговоры с родственниками, а также телеканалы как источники информации ожидаемо оказались среди лидеров, но при этом большой удельный вес в обозначенном качестве занимают иноязычные сайты, что, очевидно, для крымской молодежи было более типично, чем для российской ещё с украинского периода. После воссоединения с Россией привычка получать информацию с иностранных сайтов сохранилась. С учетом того, что за рубежом Крым считается аннексированным, в западных СМИ преобладает соответствующая этой установке риторика при оценке современной ситуации на полуострове. Усугубление некоторых проблем, о которых говорили респонденты, в иностранных СМИ напрямую связывается с изменением международного статуса региона. Под обоснование этой мысли работают информационные порталы, газеты, социальные сети и т.п., домены которых располагаются за границей. Пропаганда облегчается тем, что в соседней Украине русский язык становится средством антироссийской политики, облегчая проведение информационной войны за вовлечение крымской молодежи в альтернативные официальным формы политического участия.

Большую роль в этом играют разного рода структуры, определяющие цель своей деятельности как правозащитную. Современные российские власти предпринимают значительные усилия для создания на полуострове официально поддерживаемых НКО подобно существующей в Ростовской области AНО «Общественный контроль» (её крымский аналог - КРОО «Правозащитный комитет “Дело чести”» [8]), но сохраняются и даже создаются новые группы, действующие как исключительно сетевые сообщества, поскольку они регистрируются под зарубежными доменами, но при этом провозглашают, что действуют на территории Крыма. Одной из таких организаций является «Крымская правозащитная группа». Ее функции шире, чем у сетевого сообщества, т. к. данная организация фактически выступает в роли информационного агентства, самопровозглашенная цель которого «содействие соблюдению и защите прав человека в Крыму путем привлечения широкого внимания к проблемам прав

Из каких источников Вы обычно узнаете о событиях, в \%

Таблица 3

\begin{tabular}{|l|c|}
\hline \multicolumn{1}{|c|}{ Варианты ответов } & $\begin{array}{c}\text { Полученный } \\
\text { результат, в \% }\end{array}$ \\
\hline Социальные сети & 66,56 \\
\hline Разговоры с родственниками, друзьями, знакомыми & 63,52 \\
\hline $\begin{array}{l}\text { Общероссийские телеканалы (по значимости): Poсcия 24, Первый канал, } \\
\text { Росссия, НТВ, Рен ТВ }\end{array}$ & 41,6 \\
\hline $\begin{array}{l}\text { Интернет (иноязычные сайты): Ютуб, Гугл, The New York Times (16\% назва- } \\
\text { ний сайтов не указали) }\end{array}$ & 34,08 \\
\hline Случайные разговоры в общественных местах, слухи & 24,16 \\
\hline Крымские телеканалы (по значимости): Крыл 24, I Крыл, Миллет, ИТВ, ИКС & 15,52 \\
\hline Общественная организация, в которой состоите & 8,8 \\
\hline Сайт КФУ & 8,8 \\
\hline Газеты (по значимости): Крымская правда, Репортер, Взгляд & 6,72 \\
\hline
\end{tabular}


человека и международного гуманитарного права на территории Крымского полуострова, а также поиску и выработки механизмов для защиты прав человека в Крыму» [9]. По сути, это антироссийская организация, функционирование которой поддерживается за счет западных финансовых источников. В более традиционном формате, как сетевое сообщество в «FВ», действует «Правозащитное движение Крыма». Территориально оно располагается на Украине, где имеет статус $\mathrm{HKO}$, но тематическая направленность связана с Крымом, что обеспечивается размещением информации о нарушениях (с точки зрения администраторов группы) прав человека на полуострове. Просмотр сетевых записей показал, что «Правозащитное движение Крыма» размещает посты исключительно этнического характера, фиксируя действия российских правоохранительных органов против крымско-татарского населения [10].

Подобного рода сетевых площадок в информационном пространстве, доступном крымской молодежи, много. Их влияние на процессы саморегуляции бесспорно, т.к. они пробуждают интерес к альтернативной интерпретации трудностей процесса интеграции Крыма в Россию, порождая в политическом сознании ценности антироссийского характера. Вследствие этого политическое участие определенной части молодежи начинает подчиняться ценностям протестного характера. Надежным индикатором для проверки масштаба протестного потенциала среди молодежи могут послужить соответствующие решения, которые прогнозировались респондентами относительно участия в президентских выборах 2018 года.

Из данных таблицы 4 видно, что группа молодежи, у которой выявлены абсентеист- ские ценности, составляет 41,14\%. Это почти половина из числа опрошенных. В данной связи нам были интересны причины нежелания идти на избирательные участки, которые назывались респондентами именно из этой группы. Чаще всего среди них преобладали политические мотивы: «недоверие ко всем без исключения кандидатам в Президенты» - 14,88\%, «неуверенность в справедливом подсчете голосов» - 16,96\%, «политические (религиозные) убеждения» - 8,93\%. Остальные варианты ответов не содержали политических акцентуаций, и их, соответственно, можно не принимать в расчет в качестве импульсов для саморегуляция политической жизни крымской молодежи. При сложении выявленных результатов получаем сумму, примерно равную сорока процентам. Это около половины от суммарного показателя в $41,14 \%$, количественно характеризующих группу отказников от президентских выборов. Соответственно, по всей выборке выделяем совокупность респондентов в 20-25\%, политические ценности которых, скорее всего, не совпадают с официальными. Именно эта группа и показывает масштаб протестного потенциала среди молодежи Крыма.

Заключение. В основе саморегуляции лежит проявление компенсаторной функции, связанной с замещением недостатка внешней организующей силы, необходимой для сохранения устойчивости социального взаимодействия. Она особенно значима в условиях социальной разбалансированности, проявляющейся в наличии несогласованных между собой целей, ценностей, интересов, свойственных разным группам социальных акторов. Особенности политической саморегуляции выражаются в том, что её механизм

Таблица 4

18 марта состоятся выборы Президента России. Намерены ли Вы голосовать, в \%

\begin{tabular}{|l|c|}
\hline \multicolumn{1}{|c|}{ Варианты ответов } & Полученный результат, в \% \\
\hline Непременно буду голосовать & 25,46 \\
\hline Скорее всего, буду голосовать & 26,07 \\
\hline Скорее всего, не буду голосовать & 12,83 \\
\hline Не собираюсь участвовать в выборах & 28,31 \\
\hline Затрудняюсь ответить & 7,33 \\
\hline
\end{tabular}


формируется из политических интересов и ценностей. Структура политической саморегуляции описана нами через операционализацию таких понятий, как политические потребности, интересы, установки и ценности, в комплексе образующие определенный тип политического сознания. Саморегуляция политической жизни крымской молодежи на современном этапе проходит в непростых условиях. Неопределенность и неустойчивость, порождающие потребность в самоорганизации, для молодежи Крыма свойственны в большей степени, чем для их сверстников из других регионов России. Это обусловлено процессами ресоциализации, замены одного типа политического сознания другим. Дополнительным импульсом к самоорганизации выступает наличие старых программ политического участия, альтернативных тем, которые поддерживаются официальной российской властью. Оценка процессов саморегуляции, проходящих в политической жизни крымской молодежи, осуществлялась через социологический опрос с применением трех эмпирических индикаторов: 1) удовлетворенность положением дел в регионе (стране); 2) артикуляция трудностей, переживаемых региональной молодежью; 3) готовность включаться в альтернативные официальным программы политического участия. Масштабность процессов саморегуляции мы поставили в зависимость от выявления протестного потенциала среди крымской молодежи. Установлено, что большая часть молодежи позитивно оценивает вхождение Крыма в состав России и видит те новые возможности, которые это объединение им предоставляет. Но имеется и определенная группа, потенциально способная искать и ищущая в реальной политике альтернативные формы саморегуляции. В анализируемой выборке выделена совокупность респондентов в 20-25\%, политические ценности которых, скорее всего, не совпадают с официальными. Именно эта группа и показывает масштаб протестного потенциала среди молодежи Крыма.

\section{Литература}

1. В Крыму школьники написали объяснительные за спетый гимн Украины [Электронный ресурс] - Режим доступа: https:// point.md/ru/novosti/v-mire/v-krimu-shkoljnikinapisali-objyasniteljnie-za-spetij-gimn-ukraini.

2. Зубок Ю.А., Чупров В.И. Социокультурный механизм саморегуляции в политической жизни молодежи // Социология власти. - 2011. - №6.

3. Шюи А. Избранное: Мир, светящийся смыслом. - М.: РОССПЭН, 2004.

4. Александров Д.В. Понятие «интерес» в современной западной социологии // Социологические исследования. - 2014. - №8.

5. Зубок Ю.А. Рефлексия в саморегуляции социально-политических взаимодействий молодежи // Социология власти. 2012. — №2.

6. Гордеева С.С. Сущность и структура социальной установки в социологии и социальной психологии // Вестник Пермского университета. Философия. Психология. Социология. - 2016. - Выпуск 3.

7. Thomas $W$., Znaniecki $F$. The Polish Peasent in Europe and America. - Chicago, Ill.: The University of Chicago Press. - 19181920. — Vol. 1.

8. Правозащитный комитет «Дело чести» [Электронный ресурс] — Режим доступа: www.facebook.com/affairofhonor.

9. Крымская правозащитная группа [Электронный ресурс] - Режим доступа: crimeahrg.org/about.

10. Правозащитное движение Крыма [Электронный ресурс] - Режим доступа: www.facebook.com/humanrights.rk.

\section{References}

1.VKrymu shkol'niki napisaliobjasnitel'nye za spetyj gimn Ukrainy [In Crimea, the students write an explanation for sung the anthem of Ukraine] [Jelektronnyj resurs] — URL: https:// point.md/ru/novosti/v-mire/v-krimu-shkoljnikinapisali-objyasniteljnie-za-spetij-gimn-ukraini.

2. Zubok Ju. A., Chuprov V.I. Sociokul'turnyj mehanizm samoreguljacii v politicheskoj zhizni molodezhi [Socio-Cultural mechanism of self-regulation in the political life of youth] // Sociologija vlasti [Sociology of power]. — 2011. — №6.

3. Shjuc A. Izbrannoe: Mir, svetjashhijsja smyslom [Selected: the World that glows with meaning]. - Moscow: ROSSPJeN, 2004.

4. Aleksandrov D. V. Ponjatie «interes» v sovremennoj zapadnoj sociologii [The Concept 
of «interest» in modern Western sociology] // Sociologicheskie issledovanija [Sociological research]. — 2014. - №8.

5. ZubokJu. A. Refleksija v samoreguljacii social'no-politicheskih vzaimodejstvij molodezhi [Reflection in self-regulation of sociopolitical interactions of youth] // Sociologija vlasti [Sociology of power]. — 2012. — №2.

6. Gordeeva S.S. Sushhnost' i struktura social'noj ustanovki $\mathrm{v}$ sociologii i social'noj psihologii [The Essence and structure of social attitudes in sociology and social psychology]// Vestnik Permskogo universiteta. Filosofija. Psihologija. Sociologija [Bulletin of Perm University. Philosophy. Psychology. Sociology]. 2016. - Issue 3.
7. Thomas $W$., Znaniecki F. The Polish Peasent in Europe and America. - Chicago, Ill.: The University of Chicago Press. - 19181920. - Vol. 1.

8. Pravozashhitnyj komitet «Delo chesti» [Human Rights Committee «Case of honor»] [Jelektronnyj resurs] — URL: www.facebook. com/affairofhonor.

9. Krymskaja pravozashhitnaja gruppa [The Crimean human rights group] [Jelektronnyj resurs] - URL: crimeahrg.org/about.

10. Pravozashhitnoe dvizhenie Kryma [The human rights movement of the Crimea] [Jelektronnyj resurs] — URL: www.facebook.com/ humanrights.rk.

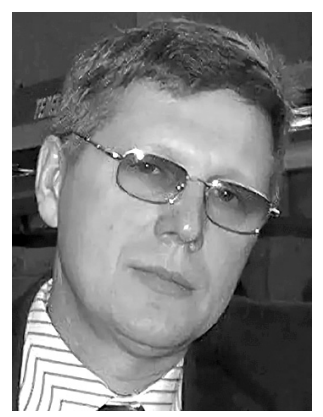

Дятлов Александр Викторович - доктор социологических наук, профессор Института социологии и регионоведения Южного федерального университета.

Dyatlov Alexander Viktorovich - Doctor of Sociological Sciences, Professor, Institute of Sociology and Regional Studies, Southern Federal University.

346500, г. Ростов-на-Дону, ул. Пушкинская, 160 160 Pushkinskaya st., 346500, Rostov-on-Don, Russia

E-mail: avdyatlov@yandex.ru 


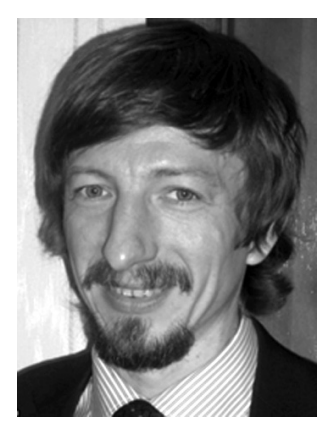

Ковалев Виталий Владимирович - доктор социологических наук, профессор Института социологии и регионоведения Южного федерального университета.

Kovalev Vitaliy Vladimirovich - Doctor of Sociological Sciences, Professor, Institute of Sociology and Regional Studies, Southern Federal University.

346500 , г. Ростов-на-Дону, ул. Пушкинская, 160

160 Pushkinskaya st., 346500, Rostov-on-Don, Russia

E-mail: vitkovalev71@gmail.com

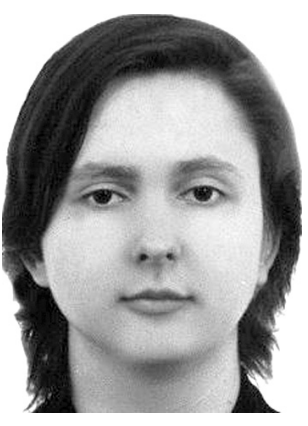

Понамарев Александр Борисович - аспирант кафедры «Теоретическая социология и методология региональных исследований» Института социологии и регионоведения Южного федерального университета.

Ponamarev Alexander Borisovich - Post-graduate Student of the Department of Theoretical Sociology and Methodology of Regional Studies, Institute of Sociology and Regional Studies, Southern Federal University.

346500, г. Ростов-на-Дону, ул. Пушкинская, 160 160 Pushkinskaya st., 346500, Rostov-on-Don, Russia

E-mail: kalvarus94@gmail.com 